\title{
Biostimulation for the Enhanced Degradation of Herbicides in Soil
}

\author{
Ramdas Gopinath Kanissery ${ }^{1}$ and Gerald K. Sims ${ }^{1,2}$ \\ ${ }^{1}$ Department of Natural Resources and Environmental Sciences, University of Illinois, 1102 S. Goodwin Avenue, Urbana, \\ IL 61801, USA \\ ${ }^{2}$ United States Department of Agriculture-Agricultural Research Service, Urbana, IL 61801, USA \\ Correspondence should be addressed to Gerald K. Sims, gksims@illinois.edu
}

Received 14 April 2011; Revised 26 June 2011; Accepted 28 June 2011

Academic Editor: Alessandro Piccolo

Copyright ( $\odot 2011$ R. G. Kanissery and G. K. Sims. This is an open access article distributed under the Creative Commons Attribution License, which permits unrestricted use, distribution, and reproduction in any medium, provided the original work is properly cited.

\begin{abstract}
Cleanup of herbicide-contaminated soils has been a dire environmental concern since the advent of industrial era. Although microorganisms are excellent degraders of herbicide compounds in the soil, some reparation may need to be brought about, in order to stimulate them to degrade the herbicide at a faster rate in a confined time frame. "Biostimulation" through the appropriate utilization of organic amendments and nutrients can accelerate the degradation of herbicides in the soil. However, effective use of biostimulants requires thorough comprehension of the global redox cycle during the microbial degradation of the herbicide molecules in the soil. In this paper, we present the prospects of using biostimulation as a powerful remediation strategy for the rapid cleanup of herbicide-polluted soils.
\end{abstract}

\section{Introduction}

The term "biostimulation" is often used to describe the addition of electron acceptors, electron donors, or nutrients to stimulate naturally occurring microbial populations [1]. Comprehensively, biostimulation could be perceived as including the introduction of adequate amounts of water, nutrients, and oxygen into the soil, in order to enhance the activity of indigenous microbial degraders [2] or to promote cometabolism [3]. "Biostimulation" is usually paired under the "enhanced bioremediation" techniques along with "bioaugmentation" which is merely the introduction of specific microorganisms (indigenous or nonindigenous) aimed at enhancing the biodegradation of target compound or serving as donors of the catabolic genes. The concept of biostimulation is to boost the intrinsic degradation potential of a polluted matrix through the accumulation of amendments, nutrients, or other limiting factors and has been used for a wide variety of xenobiotics [4]. Even though the diversity of natural microbial populations apparently displays the potential for contaminant remediation at polluted sites, factors such as lack of electron acceptors or donors, low nitrogen or phosphorus availability, or a lack of stimulation of the metabolic pathways responsible for degradation can inhibit or delay the remediation. In these cases, accumulation of exogenous nutrients can enhance the degradation of the toxic materials [5].

Herbicides are a group of compounds that, in spite of their benefits, may produce a wide range of toxic side effects which pose a potential threat to the environment. Extensive use of herbicides poses some far-reaching consequence because of the potential runoff and leaching of these compounds through the soil leading to contamination of surface and ground water [6]. Apart from this, literature suggests an array of possible toxicological implications of the persisted herbicides on the ecosystem [7]. As a result, a wealth of research has been published on the occurrence, fate, and effects on human health and environment from the use of herbicides in weed control $[8,9]$. Of the many processes contributing to herbicide fate, those mediated by microorganisms (particularly biodegradation) tend to be the most difficult to predict. Issues such as herbicidal functional efficacy, carry-over damage to future crops, leaching to groundwater, and the need to cleanup spill sites have nonetheless 
necessitated understanding of what determines herbicide degradation rates in situ. Most environmental fate processes, including sorption, hydrolysis, volatilization, transport, and accumulation of bound residues, are coupled with degradation in the environment [10]. Each of these processes may respond differently to environmental conditions; thus, in order to effectively use biostimulation for enhancing herbicide degradation, it is important to consider the impact of process coupling on remediation goals. By considering the system as a whole, it is possible to develop efficient cleanup strategies to remove herbicides and their toxic degradation products from contaminated environmental compartments. Here, we portray the relevant research outcomes that identify biostimulation as a pragmatic approach for the enhanced degradation of herbicide residues in the soil. The purpose of this paper is to abate the ambiguity in embracing biostimulation as a viable remediation strategy for the cleanup of herbicides from contaminated soils.

\section{Microorganisms: key Herbicide Degraders in the Soil}

Microbes do extremely well in thriving on herbicide compounds in the soil by utilizing them as a supply of nutrients and energy. Many herbicides serve as good carbon and/or nitrogen sources for soil microorganism [11]. Evidence for their remarkable range of degradative abilities can be seen in the recycling rather than accumulation of vast quantities of biological materials that have been produced throughout the history of life on earth [12]. Microbial degraders work in natural environments, and some alterations are imperative to encourage the organisms to degrade the herbicide at a faster rate in a limited time frame. Hence, to achieve successful bioremediation of herbicide contamination, it necessitates the construction of a unique niche for the desired microbes, so they can be productively exploited [13]. Biostimulation plays a role here, by the facile addition of substrates or nutrients to the microbial habitat strictly on a "need only" basis consequently invigorating the biodegradation of target herbicide compound.

\section{Biostimulation: Relevant Remediation Approach}

Although bioaugmentation proved to be an effective detoxification technique for the rapid cleanup of herbicides, there are reports of its failure for the full-scale field remediation [14]. Apart from this, cost ineffectiveness and uncertain long-term ecological consequences of exotic cultures add to the concern. This fact identifies the stimulation of naturally occurring consortia of herbicide-degrading microorganism as a more amicable solution for the remediation of herbicidecontaminated soils [4]. However, the selection of the right choice from these two methods varies with the perception of different practitioners in the area [15]. Acclimation lag phases have been reported for the degradation of many herbicides in soil which could be attributed to a need for a period during which selection and proliferation of a small population of the indigenous degradative microorganisms occurs. Genetic mutation, gene rearrangement, and acquisition of genetic material by horizontal gene transfer are some other explanations for this lag phase in the mineralization of the herbicides [16]. An extended acclimation phase prior to the onset of mineralization may have environmental significance and creates a "leaching window" during which herbicides could easily reach the ground water. Hence, in spite of the fact that the soil had intrinsic potential for herbicide degradation, prolonged acclimation could make in situ bioremediation an unappealing option [17]. Such instances make biostimulation a crucial strategy to reduce the acclimation lag phases and to trigger mineralization, thus affecting the rapid removal of excess herbicide from the contaminated soil.

Biostimulation techniques have already been extended to the removal of wide array of environmental contaminants besides herbicides and evolved with great success. For instance, chlorinated solvents like chlorobenzenes are a priority environmental pollutant listed by the US Environmental Protection Agency and are used mainly as intermediates in the synthesis of pesticides and other chemicals. Widespread use of these compounds has led to traces detected in soil and ground water contamination. In the recent past, a concurrent laboratory and pilot-scale study was undertaken to investigate the possibility of stimulating the native microflora with nutrients and varying levels of organic amendments for enhancing the degradation of chlorobenzenes (CBs) and 1,2-dichloro benzenes (DCBs) in the soil. The findings from the pilot-scale trial confirmed that biostimulation, with inorganic nutrients and low levels of organic material (mulch), was as effective as soil composting in the removal of DCB and CB [18].

\section{Bioavailability: Indispensable Determinant of Biodegradation}

Degradation of herbicides can be limited by bioavailability, as the compounds may be sorbed to soil solids, physically entrapped in micropores, or simply distributed through a much greater portion of the pore volume than are the degraders, thus leading to diffusion-limited degradation kinetics $[19,20]$. Generally, bioavailability of solutes increases (due to the greater continuity of water films) when pores contain substantial amounts of water [21]. Bioavailability of the contaminants may also be enhanced by the introduction of various surfactants, including biosurfactants synthesized by microorganisms. Kosaric [22] made an observation of increased degradation of metolachlor and 2,4dichlorophenol (2,4-dichlorophenoxyacetic acid metabolite) after adding the biosurfactant "sophorose lipids" to a slurry bioreactor containing soil in suspension. Mata-Sandoval and coworkers appraised the effectiveness of rhamnolipids, biosurfactants produced by Pseudomonas aeruginosa to solubilize [23] and degrade [24] pesticides like atrazine, trifluralin, and coumaphos. Authors concluded that the bioavailability of the contaminants might be increased in the presence of (bio) surfactants, though their enhanced 
degradation could not be guaranteed with the addition of surfactants.

Immobilization of contaminants in soil may lead to a considerable reduction in the bioavailability of contaminants and may restrict their leaching into groundwater, thus the factors governing bioavailability pose great environmental implications. Organic matter addition to the soil may dramatically reduce the bioavailability of herbicides (immobilize them) to preclude uptake by sensitive organisms, thus rendering them less toxic. Xenobiotic immobilization is an extension of the natural process of "bound residue" formation, in which organic compounds added to soil become less available over time, in part due to covalent bond formation with organic matter in a process analogous to humic formation. Humic substances resulting from organic matter decomposition are the major binding ligands involved in the incorporation of contaminants into the soil matrix through stable chemical linkages $[25,26]$. The herbicide bentazon was shown to undergo oxidative coupling with humic monomers (catechol, caffeic acid, protocatechuic acid, and syringaldehyde) in the presence of fungal laccase [27]. Potential for soil decontamination via such immobilization processes was recently reviewed by Bollag [28]. Conversely, this approach may not result in the destruction of the contaminant and thus raises concern over future release, and numerous studies have evaluated this possibility.

\section{Organic Amendments: Incredible Microbial Energizers}

The concept of biostimulation of herbicide degradation in soil may be dated back to earlier efforts where it was achieved simply by "land farming techniques," involving dilution of contaminated soil with uncontaminated soil. Such dilution of the contaminated soil would stimulate the biodegradation, owing to the increase in activity of soil dehydrogenase [29]. Later various organic amendments and bioprocessed materials have been investigated through the course of time as potential agents for the stimulation of native microflora for the enhanced degradation of herbicides (Table 1).

Recent research interest is focused around the outcome of "exogenous organic matter application" on the fate of herbicides in soil. The improvement in soil biological quality subsequent to the addition of organic matter has been unambiguously acknowledged [30]. Mostly these organic amendments and bioprocessed materials are composed of peptides, aminoacids, carbohydrates, lipids, and so forth. Upon addition to the soil, they are claimed to work through diverse mechanisms that encompass activation of soil microbial activity and promotion or augmentation of the activities of critical soil enzymes, which would ultimately increase the microbial populations. Subsequently, these amendments could enhance the herbicide degradation and mineralization, being an experimental way for self-cleaning of polluted areas utilizing the activities of indigenous degrading microorganisms [31]. Mineralization is construed as the complete aerobic or anaerobic degradation of the herbicide compounds to form carbon dioxide and water.
The dearth of adequate decomposable organic matter in the soil gives insufficient substrate to stimulate microorganisms in the decomposition of herbicides [32] and thus leaves herbicides recalcitrant in the soil for years without degradation. For instance, simazine, a residual nonselective herbicide, remained in soil for about 4 years after application [33]. The addition of organic matter, bioprocessed materials or compost naturally initiates the microbial activity in the soil and could be utilized to treat contaminated soils [34]. Fresh bioprocessed materials serve as rich source of nitrogen, carbon, and other nutrients and make excellent candidates for flourishing the microbial growth [4]. The general conclusion from the studies involving organic amendments in the soil was that the herbicide concentrations in the soil were reduced to significantly lower levels within short spans of time when compared to the unamended treatments. For that reason, the authors consensually corroborated the application of organic matter as a possible stimulant for the degradation of herbicides in soil.

\section{Nutrient Addition: Antidote for "Nutrient Limitation"}

Mostly, nutrients in the soil stay below optimal concentration for microbial activity. Supplementing such soils with the necessary nutrients instigates the biodegradation of the pollutants and is a promising technique to enhance the bioremediation of contaminated sites. Nutrients like carbon, nitrogen, and phosphorus stimulate microbes to create the essential enzymes to break down the contaminants. The nutritional requirement of carbon to nitrogen ratio is around $10: 1$, and carbon to phosphorus ratio is $30: 1$ [35].

In one of the earliest reports of successful biostimulation of herbicide degradation, Hance [36] demonstrated the consequence of inorganic nutrient addition on the breakdown of atrazine in the soil. The addition of inorganic salts like ammonium nitrate, potassium nitrate, and ammonium phosphate significantly decreased the half-life of herbicides in soil. Thereafter, the concept of nutrient supplementation for enhanced degradation of contaminants was brought into the limelight by various researchers, and the prospects of microbial biostimulation through the manipulation of organic and inorganic nutrient status in the soil have since been investigated (Table 2). In some cases, inorganic nitrogen starvation may be more effective in promoting degradation and has been reported for atrazine and other heterocyclic compounds $[37,38]$. This can potentially be accomplished by supplying excess carbon to make nitrogen limiting.

Recently, Qiu et al. [11] confirmed that P was a limiting nutrient during the degradation of coexisting dichlobenil and atrazine by bacterial degraders in soil. Dichlobenil was completely degraded in 60 hours in the P-supplemented soil extract, in comparison to less than $40 \%$ degradation without $\mathrm{P}$ supplement. It is noteworthy that the degree of enhancement of atrazine degradation was even greater, in that it was completely degraded in P-supplemented extract within 40 hours, compared to less than $10 \%$ degradation without the $\mathrm{P}$ supplement. 
TABLE 1: Use of organic amendments and bioprocessed materials for the enhanced degradation of herbicides.

\begin{tabular}{|c|c|c|c|}
\hline Amendment $(\mathrm{s})$ & Target herbicide(s) & Major finding & Reference \\
\hline Animal manure and sewage sludge & Atrazine and alachlor & $\begin{array}{l}\text { Herbicide degradation has been stimulated by } \\
\text { the amendments }\end{array}$ & {$[39]$} \\
\hline Activated sludge & Atrazine and simazine & $\begin{array}{l}\text { Achieved a biodegradation of } 25.2 \text { and } 32.8 \% \text {, } \\
\text { respectively, in } 9 \text { hours }\end{array}$ & {$[40]$} \\
\hline Sewage sludge and corn meal & Alachlor and trifluralin & $\begin{array}{l}\text { Significant dissipation of herbicide achieved in } \\
\text { amended treatments }\end{array}$ & {$[41]$} \\
\hline Maize straw & Methabenzthiazuron & $\begin{array}{l}\text { Significantly enhanced the degradation and } \\
\text { mineralization of the herbicide }\end{array}$ & {$[42]$} \\
\hline Dairy manure & Atrazine & $\begin{array}{l}\text { Identified as a successful technique to enhance } \\
\text { the remediation of herbicide-contaminated soil }\end{array}$ & {$[43]$} \\
\hline Dairy manure & Atrazine & $\begin{array}{l}\text { Lag period prior to herbicide degradation was } \\
\text { significantly shortened in manure-treated plot }\end{array}$ & {$[44]$} \\
\hline Cornmeal, rye grass, and poultry litter & $\begin{array}{l}\text { Cyanazine and } \\
\text { fluometuron }\end{array}$ & $\begin{array}{l}\text { All the amendments enhanced the herbicide } \\
\text { degradation and facilitated mineralization }\end{array}$ & {$[45]$} \\
\hline $\begin{array}{l}\text { Plant residues, ground seed, or commercial } \\
\text { meal }\end{array}$ & $\begin{array}{l}\text { Alachlor, metolachlor, } \\
\text { atrazine, and trifluralin }\end{array}$ & $\begin{array}{l}\text { Acknowledged the use of organic amendments } \\
\text { as an inexpensive option for the disposal of } \\
\text { herbicide waste }\end{array}$ & {$[46]$} \\
\hline Cellulose, straw, and compost & Atrazine & $\begin{array}{l}\text { Organic matter addition stimulated the } \\
\text { herbicide dealkylation in nonadapted soils }\end{array}$ & {$[47]$} \\
\hline $\begin{array}{l}\text { Compost, corn stalks, corn fermentation } \\
\text { by-product, peat, manure, and sawdust }\end{array}$ & $\begin{array}{l}\text { Atrazine, trifluralin, and } \\
\text { metolachlor }\end{array}$ & $\begin{array}{l}5 \% \text { addition of amendments resulted in } \\
\text { significant increase in bacterial population and } \\
\text { dehydrogenase activity }\end{array}$ & {$[48]$} \\
\hline Raw olive cake & $\begin{array}{l}\text { Chlorsulfuron, } \\
\text { prosulfuron, and } \\
\text { bensulfuron }\end{array}$ & $\begin{array}{l}\text { Stimulated the microbial dehydrogenase } \\
\text { activity }\end{array}$ & {$[49]$} \\
\hline $\begin{array}{l}\text { Biogas slurry, mushroom spent compost, } \\
\text { and farm yard manure }\end{array}$ & Atrazine & $\begin{array}{l}\text { Atrazine dissipation was observed to be highest } \\
(34 \%) \text { with biogas slurry }\end{array}$ & {$[4]$} \\
\hline $\begin{array}{l}\text { Rice straw, farm yard manure, saw dust, and } \\
\text { charcoal }\end{array}$ & Atrazine & $\begin{array}{l}\text { Farm yard manure was found to be the most } \\
\text { effective for the degradation of herbicide } \\
\text { ( } 89.5 \% \text { degradation in } 60 \text { days) }\end{array}$ & {$[50]$} \\
\hline
\end{tabular}

Additional evidence for the successful biostimulation of herbicide degradation was reported by Lipthay et al. [51]. The authors showed that the mineralization rate of a greater herbicide concentration was significantly stimulated by the addition of nutrients. The amendments of both minimal medium $\left(\mathrm{Cl}^{-}, \mathrm{PO}_{4}{ }^{2-}, \mathrm{SO}_{4}{ }^{2-}, \mathrm{Na}^{+}, \mathrm{K}^{+}, \mathrm{NH}^{4+}\right.$, $\mathrm{Mg}^{2+}, \mathrm{Mn}^{2+}, \mathrm{Fe}^{2+}$, and $\left.\mathrm{Zn}^{2+}\right)$ and Casamino acid to the soil sediment resulted in a decrease in the mineralization lag phase of about 30 days for 2,4 dichlorophenoxyacetic acid (2,4-D) and 45 days for mecoprop at a greater herbicide concentration. Also, the addition of glucose and phosphate significantly enhanced the extent of mineralization for 2,4$\mathrm{D}$ and mecoprop at a low herbicide concentration. The heterotrophic bacterial density was shown to increase as a result of these nutrient amendments. The authors attributed the enhanced degradation of herbicides to the presence of inorganic nutrients such as phosphate and nitrogen. Conversely, the lack of such nutrients in soil could suppress the mineralization of herbicide when they are used as carbon sources for microbial growth.

Mineralization and degradation of the herbicide mecoprop by selected Pseudomonas species was purported to be improved in the presence of nutrient-rich medium. Results from the study clearly showed that the herbicide degrader's metabolic activity was enhanced with the amendment of nutrients and confirmed a positive correlation between the soil nutrient content and herbicide biodegradation [52]. The addition of nitrate to a dormant iron-reducing microcosm successfully stimulated the anaerobic biodegradation of (R)mecoprop after a lag period of about 20 days and resulted in the production of the metabolite, 4-chloro 2-methylphenol [53]. Nitrogen and phosphorus, when applied, influenced the degradation of isoproturon in soil by converting the herbicide into a complex degradation product, 4, 4' diisopropylazobenzene [54].

Addition of "organic nutrient" sources could also aid in the cleanup of herbicides from contaminated soil. Dicloflop, a postemergent herbicide, was readily mineralized by the bacterial degraders when supplied with an additional carbon source in the form of tryptic soy broth [55]. Assaf and Turco [56] observed that addition of mannitol (carbon source) to the soil after 140 days increased the $\left[{ }^{14} \mathrm{C}\right]$ carbon dioxide evolution as a result of enhanced mineralization of atrazine. Better dealkylation of atrazine in adapted soil was 
TABLE 2: List of nutrient supplements used for stimulating the biodegradation of herbicides in soil.

\begin{tabular}{lcc}
\hline Nutrient(s) & Target herbicide(s) & Reference \\
\hline $\begin{array}{l}\text { Ammonium nitrate, } \\
\text { potassium nitrate, and } \\
\text { ammonium phosphate }\end{array}$ & Atrazine & {$[36]$} \\
$\begin{array}{l}\text { Phosphorus (P) } \\
\text { Minimal nutrient } \\
\text { medium, casamino acid, } \\
\text { glucose, and phosphate }\end{array}$ & 2,4-D and mecoprop & {$[11]$} \\
$\begin{array}{l}\text { Nitrate } \\
\text { Nitrate and phosphorus } \\
\text { Tryptic soy broth }\end{array}$ & (R)-mecoprop & {$[51]$} \\
$\begin{array}{l}\text { Mannitol } \\
\text { Glucose }\end{array}$ & Isoproturon & {$[53]$} \\
& Diclofop & {$[55]$} \\
& Atrazine & {$[56]$} \\
\end{tabular}

detected with the addition of a large amount of glucose [57]. Likewise, there have been reports of enhanced mineralization of atrazine following the addition of glucose $[58,59]$. The effects of added carbon on atrazine degradation may be the indirect result of making nitrogen limiting, thereby enhancing access of atrazine as a nitrogen source. Improved biodegradation of contaminants with the addition of nonchlorinated organic compounds [60] and readily available carbon sources like glutamate, aspartate, succinate, acetate, glucose, and cellobiose [61] have also been accounted in earlier studies.

The concept of biostimulation has also been extended to other compartments of the environment and evolved with great success. The role of nutrients on the biotransformation of herbicides in aquatic milieu has also been explored thoroughly. Alachlor [62, 63], simazine [64], MCPA [64], and 2,4-D [65] are a few examples of the herbicides probed for the correlation between enhanced biodegradation and elevated nutrient status in aquatic systems.

\section{Thermodynamic Intervention: Use of Electron Donors and Acceptors}

In unsaturated soil, solutes, such as herbicides, exhibit limited availability due in part to the requirement to diffuse through tortuous pore space and thin or discontinuous water films. Under saturated conditions, aqueous diffusion is maximized for solutes, however, movement through the vapor phase ceases. Among the most profound consequences of this transition is a 10,000-fold decrease in the diffusive supply of oxygen. After soil is inundated with water, biological and chemical oxygen demand will result in the rapid depletion of $\mathrm{O}_{2}$, which is only soluble at about $8 \mathrm{mg} / \mathrm{Kg}$. The result is succession of microbial heterotrophic communities adapted to utilize a variety of potential electron acceptors as conditions become suitable for their activities. Figure 1 depicts a hypothetical data set obtained when key electron acceptors (or their reduced products) are monitored after a soil is flooded. Data from the research work by Tor et al. [66] was

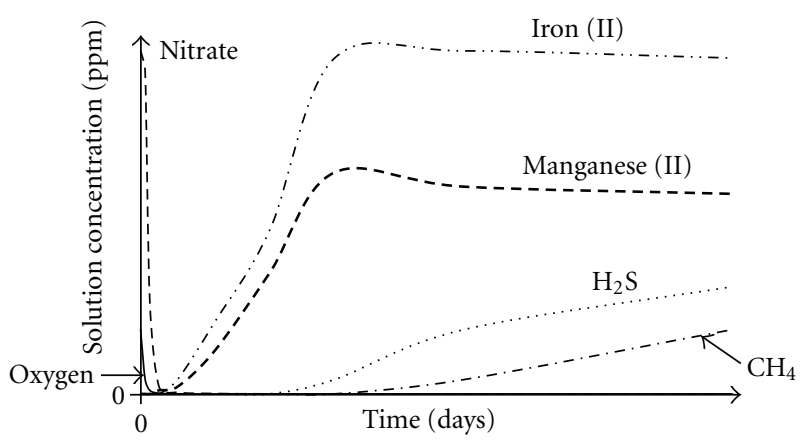

FIGURE 1: Typical temporal pattern for sequential reduction of electron acceptors assuming soil is inundated with water on day zero.

in compliance with a similar pattern of sequential reduction where the authors noted the accumulation of Fe(II) immediately following the depletion of nitrate. It follows that biodegradation may, in some cases, be stimulated by supplementing with specific electron acceptors.

The use of nitrate as an alternate electron acceptor to oxygen is widespread among Eubacteria, and a few organisms have been shown to degrade various herbicides under denitrifying conditions. For example, Ralstonia sp. strain M91-3 [67] and Pseudomonas sp. strain ADP [68] appear to degrade atrazine using nitrate as an electron acceptor. Imposition of denitrifying conditions may not, however, be an adequate treatment to take advantage of anoxic conditions, as degradation of the herbicide mecoprop occurred at only low rates under either denitrifying or methanogenic sediments, whereas there was little or no evidence for degradation of atrazine, isoproturon, or metsulfuron-methyl in anoxic media [69]. In some cases, addition of an inoculum may be needed, as in the case of atrazine degradation by Pseudomonas sp. strain ADP when inoculated into anoxic sediments treated with nitrate [70].

Typically, after complete depletion of nitrate, soils and sediments undergo iron-reducing conditions [66], which involves a significant change in community composition $[71,72]$. Several herbicides have been reported to undergo accelerated transformation in soils under iron-reducing conditions, though in most of these cases, it has not been clear that iron-reducing bacteria were directly involved in herbicide degradation. Using cultures of Comamonas koreensis CY01, Wu et al. [73] demonstrated iron reduction coupled to degradation of the herbicide, 2,4-dichlorophenoxyacetic acid $(2,4-\mathrm{D})$. Several dinitroaniline herbicides $[66,74]$, as well as alachlor and atrazine [75], appear to be transformed instead by microbially reduced iron minerals. Such biologically mediated abiotic transformation may be a promising approach for deactivating these compounds though it is apparent that a great deal of the original herbicide may remain in the soil as unavailable bound residues.

Many herbicides contain halogens, which under aerobic conditions tend to undergo slower degradation kinetics for both homocyclic [76] and heterocyclic compounds [77]. However, under anaerobic conditions, reductive dehalogenation may be very effective at detoxifying herbicides and 
may initiate a more complete degradation process. Examples of herbicides that have been shown to be subject to reductive dechlorination include alachlor, metolachlor, and propachlor [78]. Both the bromine and iodine atoms have also been shown to be removed from certain herbicides (e.g., bromoxynil and ioxynil) by known chlorine respiring bacteria, such as Desulfitobacterium chlororespirans [79].

\section{Biostimulation: Cynical Aftermaths}

Enhanced mineralization of contaminants in natural habitats by nutrient addition will require proper knowledge of natural microbial communities and their growth requirements [55]. Contrary to all the success stories, literature mentions the possible inhibitory effects of organic amendments and nutrient addition on herbicide mineralization in soil. The reduction in microbial degradation of herbicides is often explained by the decrease of pesticide availability after increase in their sorption [80]. Herbicide degradation in soils amended with organic materials can be modified, depending on the organic amendment and the herbicide properties. Herbicides generally adsorb readily to the organic matter. Hence, organic amendments favoring the sorption of herbicides can reduce their microbial bioavailability and repress their biodegradation [81]. For instance, organic amendments added to the soil decreased atrazine mineralization due to increased sorption of the herbicide to the soil [82].

High concentrations of mineral $\mathrm{N}$ significantly decreased atrazine mineralization in the soil [83]. Entry et al. [84] elucidated the suppression of atrazine and 2,4-D mineralization in the soil following the addition of mineral $\mathrm{N}$ in the form of ammonium nitrate. Triazine-ring mineralization related to specific microflora was inhibited when large concentrations of glucose and mineral $\mathrm{N}$ were added to the soil. The authors observed a significant increase in the total microbial biomass under elevated concentration of glucose and mineral nitrogen in the soil [57]. The reduced mineralization of the herbicide under such conditions could be attributed to the competition for space and nutrients between the herbicide-degrading microorganisms [83]. Despite demonstrating potential for effective use of biostimulation, the above findings bid for more work in the area in order to consider the approach as a fully dependable candidate for herbicide bioremediation in the soil.

\section{Lab to Field Dilemma}

To date, most of the soil biostimulation experiments have been carried out in the lab (controlled conditions), while the results from field experiments are sparse. The paradox of achieving as good or better results in the field as in the lab is the greatest challenge to face in implementing a bioremediation strategy [85]. The applicability of biostimulation technology at an actual site necessitates the knowledge of natural process at the contaminated site together with meticulous information of microbial degradation developed in the laboratory [13]. The degradative microorganisms face competition with other organisms in the field for nutritional and physical resources, thus creating a major impediment for the expected bioconversion [86]. Hence, it is imperative to test the feasibility of the technology in a situation comparable to the actual intervention, such as a mesocosm or pilot study after the initial microcosm experiment [15].

\section{Biostimulation: Field-Scale Feasibility}

The effectiveness of field-scale bioremediation designs is subjected to scale-dependent variables such as mass transport limitations and spatial heterogeneity [87]. Lima et al. [88] successfully transferred a previously examined "small-scale biostimulation strategy" of atrazine to a larger open soil conditions spiked with commercial formulation at doses, mimicking overuse or concentration "hot spots" that may arise from the uneven application and spill scenarios. In another field evaluation experiment, Strong et al. [89] assessed a range of biostimulation supplements to optimize the nutritional additives and applied this information to the field to test systematically the ability of different bioremediation methods to remediate soil heavily contaminated with atrazine by an accidental spill.

Unfortunately, little information is available on the field trials of the biostimulation efforts for the in situ remediation of herbicide contamination in agriculture lands. However, literature supports the incorporation of the concept of biostimulation into ad situ and ex situ bioremediation techniques such as slurry bioreactors as a more suitable alternative. For instance, the remediation of a mineral agricultural soil contaminated with 2,4-dichlorophenoxyacetic acid (2,4-D) was evaluated using aerobic and sulphate-reducing slurry bioreactors. The effect of the sucrose amendment on 2,4$\mathrm{D}$ removal was also assessed. Results suggested that aerobic removal was not affected by the sucrose supplementation, whereas the removal of the herbicide in sulphate-reducing slurry bioreactors significantly improved with sucrose [90].

Although utilization of the varying soil redox potential could be considered under the broad definition of biostimulation, soil aeration in situ is mostly impractical due to both logistics and cost. Terrestrial soil environments can be considered as being dominated by aerobic conditions, but there are situations when anaerobiosis prevails. The oxygen supply rate depends on the moisture content and the physical characteristics of the soil, especially porosity which is influenced by structure and texture. A change in either the rate of oxygen consumption or supply can bring about anaerobiosis, for example, a large application of manure or by compaction of the soil. Most soil anaerobiosis is caused by excessive soil moisture resulting from a high water table or heavy rains. Occurrence of such anaerobic microsites in the soil could aid in the cleanup of agricultural soils contaminated with herbicides whose microbial degradation occurs primarily through anaerobic pathways.

The prospect of adding inorganic fertilizers into agriculture soil for stimulating the microbial degradation of contaminants in the soil has been investigated by several workers. Recently, Tortella et al. [91] demonstrated the increased degradation of the insecticide chlorpyrifos using 
an agricultural biobed system biostimulated with inorganic fertilizer (NPK). In yet another study, McGhee and Burns [92] reported the significant increase in degradation of herbicides 2,4-D and 4-chloro-2-methylphenoxyacetic acid (MCPA) following the addition of a combined NPK fertilizer.

Even though addition of nitrate or other inorganic fertilizers to nutrient-poor soils is a realistic biostimulation option for field-scale remediation of herbicide-contaminated soil, any supplementations to overcome possible soil nutrient limitations must be made with extreme care. McBain et al. [93] attempted a pilot field study of the bioremediation of MCPAcontaminated soil by supplementing nitrate to the soil without much success. The authors accounted that nitrate is not suitable as an alternative electron acceptor for MCPA degradation and, in certain circumstances, inhibits aerobic catabolism of the herbicide in the soil. Also, excessively applied inorganic nutrients into the agricultural soil in the pretext of biostimulation may be subject to runoff, resulting in unacceptable levels of water pollution [94]. Such dissolved inorganic nitrogen and phosphorus, as well as the prevailing weather, trigger the primary production and hence the detrimental eutrophication (hypertrophication) process in surface waters [95].

\section{Future Prospects}

Herbicides are listed among those functional compounds that have less favorable prospects of recycling through the microbial biodegradation network. Copious amounts of compounds which are produced in large quantities by the industry may not have a chance of being perfectly degraded through microbial metabolism. Henceforth, biodegradation prediction systems are desperately needed as screening tools to provide insight for bringing the theoretical know-how into practice [3]. A center and a database (http://umbbd.msi .umn.edu) have been established for elucidating the biodegradation of xenobiotic compounds including herbicides [12]. Degradation prediction models of herbicide molecules may be combined with the strategic manipulation of microbial thermodynamic deficit and could be utilized as a framework for the successful biostimulation of their microbial biodegradation.

The combination of "bioaugmentation and biostimulation" might be another promising plan of action to hasten the biodegradation of recalcitrant herbicide compounds. The addition of energy sources or electron acceptors may benefit both indigenous and exogenous degraders [15]. Silva et al. [17] developed a joint bioaugmentation and biostimulation approach for the cleanup of soil contaminated with a high concentration of atrazine. Bioaugmentation with Pseudomonas sp. ADP alone resulted in a limited improvement in the atrazine mineralization. On the contrary, bioaugmentation together with the addition of citrate and succinate as biostimulants evidently increased the bacterial degrader's cell survival and thus herbicide mineralization. In essence, coupled with advances in biotechnology and utilizing the omics data on many soil degrading microorganisms, biostimulation holds a vivid future in framing viable technology for the removal of herbicide contaminants from the environment.

In spite of the conflicting results from the literature, biostimulation still remains viable as an empirical in situ herbicide bioremediation technology. The existence of competent microorganisms for a given herbicide pollutant, along with suitable growth conditions, should be initially determined by laboratory and field trials. Such information would allow the exploitation of environmental factors that may limit or prevent the biodegradation of pollutants at the actual contamination site. Based on these considerations, a better understanding of microbial degradation abilities, together with their metabolic networks as well as their cellular resistance and adaptation mechanisms, will bring out an excellent cleanup strategy tailored for a specific contaminant in a specific site [96].

\section{Conclusion}

Herbicides are a group of organic compounds that possess far-reaching environmental consequences when persistent in the soil. Microorganisms are capable of degrading the herbicide compounds in the soil by utilizing them as a supply of nutrients and energy. Better microbial bioavailability of herbicides in the soil could be achieved by the use of surfactants and would set up an excellent premise for their enhanced degradation in the contaminated soil. However, lack of organic matter and nutrients in the soil can hinder microbial activity and induce a lag phase in the mineralization of herbicide contaminant. "Biostimulation" through the application of organic amendments and nutrients into the soil can overcome these inhibitions and accelerate the removal of herbicides from the soil. Successful degradation of herbicides in soil necessitates deep insight into the thermodynamic processes occurring during their microbial consumption, consecutively applying the information towards the judicious use of electron donors and acceptors for the effective stimulation of microbial activity. Although it requires extensive field evaluation studies, biostimulation in conjunction with other bioremediation tools is definitely a promising technique for the removal of herbicide wastes from the soil.

\section{Acknowledgments}

The authors thank Yongsong Cao (China Agricultural University) and Xianhui $\mathrm{Fu}$ (University of Illinois at Urbana Champaign) for their valuable suggestions during the preparation of the paper. Mention of trade names or commercial products in this paper is solely for the purpose of providing scientific information and does not imply recommendation or endorsement by the U.S. Department of Agriculture.

\section{References}

[1] K. M. Scow and K. A. Hicks, "Natural attenuation and enhanced bioremediation of organic contaminants in groundwater," Current Opinion in Biotechnology, vol. 16, no. 3, pp. 246-253, 2005. 
[2] M. N. P. F. S. Couto, E. Monteiro, and M. T. S. D. Vasconcelos, "Mesocosm trials of bioremediation of contaminated soil of a petroleum refinery: comparison of natural attenuation, biostimulation and bioaugmentation," Environmental Science and Pollution Research, vol. 17, no. 7, pp. 1339-1346, 2010.

[3] V. de Lorenzo, "Systems biology approaches to bioremediation," Current Opinion in Biotechnology, vol. 19, no. 6, pp. 579$589,2008$.

[4] N. Kadian, A. Gupta, S. Satya, R. K. Mehta, and A. Malik, "Biodegradation of herbicide (atrazine) in contaminated soil using various bioprocessed materials," Bioresource Technology, vol. 99, no. 11, pp. 4642-4647, 2008.

[5] L. Cosgrove, P. L. McGeechan, P. S. Handley, and G. D. Robson, "Effect of biostimulation and bioaugmentation on degradation of polyurethane buried in soil," Applied and Environmental Microbiology, vol. 76, no. 3, pp. 810-819, 2010.

[6] M. Graymore, F. Stagnitti, and G. Allinson, "Impacts of atrazine in aquatic ecosystems," Environment International, vol. 26, no. 7-8, pp. 483-495, 2001.

[7] I. Buchanan, H. C. Liang, W. Khan et al., "Pesticides and herbicides," Water Environment Research, vol. 81, no. 10, pp. 1731-1816, 2009.

[8] J. M. Bollag and S. Y. Liu, "Biological transformation processes of pesticides," in Pesticides in the Soil Environment: Processes, Impacts, and Modeling, pp. 169-211, Soil Science Society of America, Madison, Wis, USA, 1990.

[9] D. W. Kolpin, E. M. Thurman, and S. M. Linhart, "The environmental occurrence of herbicides: the importance of degradates in ground water," Archives of Environmental Contamination and Toxicology, vol. 35, no. 3, pp. 385-390, 1998.

[10] G. K. Sims and A. M. Cupples, "Factors controlling degradation of pesticides in soil," Pesticide Science, vol. 55, no. 5, pp. 598-601, 1999.

[11] Y. Qiu, H. Pang, Z. Zhou, P. Zhang, Y. Feng, and G. D. Sheng, "Competitive biodegradation of dichlobenil and atrazine coexisting in soil amended with a char and citrate," Environmental Pollution, vol. 157, no. 11, pp. 2964-2969, 2009.

[12] M. Dua, A. Singh, N. Sethunathan, and A. Johri, "Biotechnology and bioremediation: successes and limitations," Applied Microbiology and Biotechnology, vol. 59, no. 2-3, pp. 143-152, 2002.

[13] D. K. Singh, "Biodegradation and bioremediation of pesticide in soil: concept, method and recent developments," Indian Journal of Microbiology, vol. 48, no. 1, pp. 35-40, 2008.

[14] N. Sethunathan, K. Raghu, H. C. Aggarwal, and R. Naidu, "Biremediation of pesticides in soils through enhancement of Indigenous microbial activities," in Proceedings of the 2nd International Conference on Contaminants in Soil Environment in Australia-Pacific Region, 1999.

[15] S. El Fantroussi and S. N. Agathos, "Is bioaugmentation a feasible strategy for pollutant removal and site remediation?" Current Opinion in Microbiology, vol. 8, no. 3, pp. 268-275, 2005.

[16] M. Alexander, "Acclimation," in Biodegradation and Bioremediation, pp. 16-40, Academic Press, San Diego, Calif, USA, 1994.

[17] E. Silva, A. M. Fialho, I. Sa-Correia, R. G. Burns, and L. J. Shaw, "Combined bioaugmentation and biostimulation to cleanup soil contaminated with high concentrations of atrazine," Environmental Science \& Technology, vol. 38, no. 2, pp. 632-637, 2004.

[18] T. F. Guerin, "Ex-situ bioremediation of chlorobenzenes in soil," Journal of Hazardous Materials, vol. 154, no. 1-3, pp. 920, 2008.
[19] G. K. Sims, J. D. Wolt, and R. G. Lehmann, "Bioavailability of sorbed pesticides and other xenobiotic molecules," in Proceedings of the International Symposium on Environmental Aspects of Pesticide Microbiology, pp. 159-164, Sigtuna, Sweden, August 1992.

[20] G. K. Sims, S. Taylor-Lovell, G. Tarr, and S. Maskel, "Role of sorption and degradation in the herbicidal function of isoxaflutole," Pest Management Science, vol. 65, no. 7, pp. 805$810,2009$.

[21] T. A. Johnson and G. K. Sims, "Introduction of 2,4dichlorophenoxyacetic acid into soil with solvents and resulting implications for bioavailability to microorganisms," World Journal of Microbiology and Biotechnology, pp. 1-7, 2010.

[22] N. Kosaric, "Biosurfactants and their application for soil bioremediation," Food Technology and Biotechnology, vol. 39, no. 4, pp. 295-304, 2001.

[23] J. C. Mata-Sandoval, J. Karns, and A. Torrents, "Effect of rhamnolipids produced by Pseudomonas aeruginosa UG2 on the solubilization of pesticides," Environmental Science \& Technology, vol. 34, no. 23, pp. 4923-4930, 2000.

[24] J. C. Mata-Sandoval, J. Karns, and A. Torrents, "Influence of rhamnolipids and triton X-100 on the biodegradation of three pesticides in aqueous phase and soil slurries," Journal of Agricultural and Food Chemistry, vol. 49, no. 7, pp. 3296-3303, 2001.

[25] J. M. Bollag, J. Dec, and P. M. Huang, "Formation mechanisms of complex organic structures in soil habitats," Advances in Agronomy, vol. 63, pp. 237-266, 1997.

[26] B. Gevao, K. T. Semple, and K. C. Jones, "Bound pesticide residues in soils: a review," Environmental Pollution, vol. 108, no. 1, pp. 3-14, 2000.

[27] J. E. Kim, E. Fernandes, and J. M. Bollag, "Enzymatic coupling of the herbicide bentazon with humus monomers and characterization of reaction products," Environmental Science \& Technology, vol. 31, no. 8, pp. 2392-2398, 1997.

[28] J. M. Bollag, "Decontamination of soils through immobilization of anthropogenic organics by biotic and abiotic catalysts," in Molecular Environmental Soil Science at the Interfaces in the Earth's Critical Zone, J. Xu and P. M. Huang, Eds., pp. 182-183, Springer, Berlin, Germany, 2010.

[29] A. S. Felsot and E. K. Dzantor, "Effect of alachlor concentration and an organic amendment on soil dehydrogenase activity and pesticide degradation rate," Environmental Toxicology and Chemistry, vol. 14, no. 1, pp. 23-28, 1995.

[30] J. A. Pascual, C. García, T. Hernandez, and M. Ayuso, "Changes in the microbial activity of an arid soil amended with urban organic wastes," Biology and Fertility of Soils, vol. 24, no. 4, pp. 429-434, 1997.

[31] M. Tejada, A. M. García-Martínez, I. Gómez, and J. Parrado, "Application of MCPA herbicide on soils amended with biostimulants: short-time effects on soil biological properties," Chemosphere, vol. 80, no. 9, pp. 1088-1094, 2010.

[32] A. S. Felsot and E. K. Dzantor, "Enhancing biodegradation for detoxification of herbicide waste in soil," ACS Symposium Series, vol. 426, pp. 249-268, 1990.

[33] C. G. Cogger, P. R. Bristow, J. D. Stark, L. W. Getzin, and M. Montgomery, "Transport persistence of pesticides in alluvial soils: I. Simazine," Journal of Environmental Quality, vol. 27, no. 3, pp. 543-550, 1998.

[34] F. Büyüksönmez, R. Rynk, T. F. Hess, and E. Bechinski, "Occurrence, degradation and fate of pesticides during composting part I: composting, pesticides, and pesticide degradation," Compost Science \& Utilization, vol. 7, no. 4, pp. 66-82, 1999. 
[35] M. Vidali, "Bioremediation. An overview," Pure and Applied Chemistry, vol. 73, no. 7, pp. 1163-1172, 2001.

[36] R. J. Hance, "The effect of nutrients on the decomposition of the herbicides atrazine and linuron incubated with soil," Pesticide Science, vol. 4, no. 6, pp. 817-822, 1973.

[37] F. Bichat, G. K. Sims, and R. L. Mulvaney, "Microbial utilization of heterocyclic nitrogen from atrazine," Soil Science Society of America Journal, vol. 63, no. 1, pp. 100-110, 1999.

[38] G. K. Sims, "Nitrogen starvation promotes biodegradation of N-heterocyclic compounds in soil," Soil Biology \& Biochemistry, vol. 38, no. 8, pp. 2478-2480, 2006.

[39] L. Guo, T. J. Bicki, A. S. Felsot, and T. D. Hinesly, "Phytotoxicity of atrazine and alachlor in soil amended with sludge, manure and activated carbon," Journal of Environmental Science and Health, Part B, vol. 26, no. 5-6, pp. 513-527, 1991.

[40] V. Leoni, C. Cremisini, R. Giovinazzo, G. Puccetti, and M. Vitali, "Activated sludge biodegradation test as a screening method to evaluate persistence of pesticides in soil," Science of the Total Environment, vol. 123-124, pp. 279-289, 1992.

[41] E. K. Dzantor, A. S. Felsot, and M. J. Beck, "Bioremediating herbicide-contaminated soils," Applied Biochemistry and Biotechnology, vol. 39-40, no. 1, pp. 621-630, 1993.

[42] H. Printz, P. Burauel, and F. Fuhr, "Effect of organic amendment on degradation and formation of bound residues of methabenzthiazuron in soil under constant climatic conditions," Journal of Environmental Science and Health, Part B, vol. 30, no. 4, pp. 435-456, 1995.

[43] J. Gan, R. L. Becker, W. C. Koskinen, and D. D. Buhler, "Degradation of atrazine in two soils as a function of concentration," Journal of Environmental Quality, vol. 25, no. 5, pp. 1064-1072, 1996.

[44] E. Topp, L. Tessier, and E. G. Gregorich, "Dairy manure incorporation stimulates rapid atrazine mineralization in an agricultural soil," Canadian Journal of Soil Science, vol. 76, no. 3, pp. 403-409, 1996.

[45] S. C. Wagner and R. M. Zablotowicz, "Effect of organic amendments on the bioremediation of cyanazine and fluometuron in soil," Journal of Environmental Science and Health, Part B, vol. 32, no. 1, pp. 37-54, 1997.

[46] A. S. Felsot and E. K. Dzantor, "Potential of biostimulation to enhance dissipation of aged herbicide residues in land-farmed waste," in Phytoremediation of Soil and Water Contaminants, E. L. Kruger, T. A. Anderson, and J. R. Coats, Eds., pp. 77-91, 1997.

[47] R. Abdelhafid, S. Houot, and E. Barriuso, "Dependence of atrazine degradation on $\mathrm{C}$ and $\mathrm{N}$ availability in adapted and non-adapted soils," Soil Biology \& Biochemistry, vol. 32, no. 3, pp. 389-401, 2000.

[48] T. B. Moorman, J. K. Cowan, E. L. Arthur, and J. R. Coats, "Organic amendments to enhance herbicide biodegradation in contaminated soils," Biology and Fertility of Soils, vol. 33, no. 6, pp. 541-545, 2001.

[49] L. Delgado-Moreno and A. Peña, "Organic amendments from olive cake as a strategy to modify the degradation of sulfonylurea herbicides in soil," Journal of Agricultural and Food Chemistry, vol. 55, no. 15, pp. 6213-6218, 2007.

[50] I. Mukherjee, "Effect of organic amendments on degradation of atrazine," Bulletin of Environmental Contamination and Toxicology, vol. 83, no. 6, pp. 832-835, 2009.

[51] J. R. de Lipthay, S. R. Sørensen, and J. Aamand, "Effect of herbicide concentration and organic and inorganic nutrient amendment on the mineralization of mecoprop, 2,4-D and 2,4,5-T in soil and aquifer samples," Environmental Pollution, vol. 148, no. 1, pp. 83-93, 2007.
[52] E. El-Bestawy and H. J. Albrechtsen, "Effect of nutrient amendments and sterilization on mineralization and/or biodegradation of 14C-labeled MCPP by soil bacteria under aerobic conditions," International Biodeterioration \& Biodegradation, vol. 59, no. 3, pp. 193-201, 2007.

[53] I. Harrison, G. M. Williams, and C. A. Carlick, "Enantioselective biodegradation of mecoprop in aerobic and anaerobic microcosms," Chemosphere, vol. 53, no. 5, pp. 539-549, 2003.

[54] C. Perrin-Ganier, F. Schiavon, J. L. Morel, and M. Schiavon, "Effect of sludge-amendment or nutrient addition on the biodegradation of the herbicide isoproturon in soil," Chemosphere, vol. 44, no. 4, pp. 887-892, 2001.

[55] G. M. Wolfaardt, J. R. Lawrence, R. D. Robarts, and D. E. Caldwell, "The role of interactions, sessile growth, and nutrient amendments on the degradative efficiency of a microbial consortium," Canadian Journal of Microbiology, vol. 40, no. 5, pp. 331-340, 1994.

[56] N. A. Assaf and R. F. Turco, "Influence of carbon and nitrogen application on the mineralization of atrazine and its metabolites in soil," Pesticide Science, vol. 41, no. 1, pp. 41-47, 1994.

[57] R. Abdelhafid, S. Houot, and E. Barriuso, "How increasing availabilities of carbon and nitrogen affect atrazine behaviour in soils," Biology and Fertility of Soils, vol. 30, no. 4, pp. 333$340,2000$.

[58] L. L. McCormick and A. E. Hiltbold, "Microbiological decomposition of atrazine and diuron is soil," Weeds, vol. 14, no. 1, pp. 77-82, 1966.

[59] G. H. Wagner and K. S. Chahal, "Decomposition of carbon14 labelled atrazine in soil samples from Sanborn field1," Soil Science Society of America Journal, vol. 30, no. 6, pp. 752-754, 1996.

[60] G. A. Barrio-Lage, F. Z. Parsons, R. M. Narbaitz, and P. A. Lorenzo, "Enhanced anaerobic biodegration of vinyl chloride in ground water," Environmental Toxicology and Chemistry, vol. 9, no. 4, pp. 403-415, 1990.

[61] E. Topp, R. L. Crawford, and R. S. Hanson, "Influence of readily metabolizable carbon on pentachlorophenol metabolism by a pentachlorophenol-degrading Flavobacterium sp," Applied and Environmental Microbiology, vol. 54, no. 10, pp. 2452-2459, 1988.

[62] A. P. Ensz, C. W. Knapp, and D. W. Graham, "Influence of autochthonous dissolved organic carbon and nutrient limitation on alachlor biotransformation in aerobic aquatic systems," Environmental Science \& Technology, vol. 37, no. 18, pp. 4157-4162, 2003.

[63] C. W. Knapp, D. W. Graham, G. Berardesco, F. DeNoyelles, B. J. Cutak, and C. K. Larive, "Nutrient level, microbial activity, and alachlor transformation in aerobic aquatic systems," Water Research, vol. 37, no. 19, pp. 4761-4769, 2003.

[64] J. P. M. Vink, G. Schraa, and S. E. A. T. M. van der Zee, "Nutrient effects on microbial transformation of pesticides in nitrifying surface waters," Environmental Toxicology, vol. 14, no. 3, pp. 329-338, 1999.

[65] H. J. Nesbitt and J. R. Watson, "Degradation of the herbicide 2,4-D in river water. II. The role of suspended sediment, nutrients and water temperature," Water Research, vol. 14, no. 12, pp. 1689-1694, 1980.

[66] J. M. Tor, C. Xu, J. M. Stucki, M. M. Wander, and G. K. Sims, "Trifluralin degradation under microbiologically induced nitrate and Fe(III) reducing conditions," Environmental Science \& Technology, vol. 34, no. 15, pp. 3148-3152, 2000.

[67] J. J. Crawford, G. K. Sims, R. L. Mulvaney, and M. Radosevich, "Biodegradation of atrazine under denitrifying conditions," 
Applied Microbiology and Biotechnology, vol. 49, no. 5, pp. 618623, 1998.

[68] I. Katz, C. G. Dosoretz, R. T. Mandelbaum, and M. Green, "Atrazine degradation under denitrifying conditions in continuous culture of Pseudomonas ADP," Water Research, vol. 35, no. 13, pp. 3272-3275, 2001.

[69] L. Larsen and J. Aamand, "Degradation of herbicides in two sandy aquifers under different redox conditions," Chemosphere, vol. 44, no. 2, pp. 231-236, 2001.

[70] N. Shapir, R. T. Mandelbaum, and G. S. Jacobsen, "Rapid atrazine mineralization under denitrifying conditions by Pseudomonas sp. strain ADP in aquifer sediments," Environmental Science \& Technology, vol. 32, no. 23, pp. 3789-3792, 1998.

[71] T. Lueders and M. Friedrich, "Archaeal population dynamics during sequential reduction processes in rice field soil," Applied and Environmental Microbiology, vol. 66, no. 7, pp. 2732-2742, 2000.

[72] N. N. North, S. L. Dollhopf, L. Petrie, J. D. Istok, D. L. Balkwill, and J. E. Kostka, "Change in bacterial community structure during in situ biostimulation of subsurface sediment cocontaminated with uranium and nitrate," Applied and Environmental Microbiology, vol. 70, no. 8, pp. 4911-4920, 2004.

[73] C. Y. Wu, L. Zhuang, S. G. Zhou, F. B. Li, and X. M. Li, "Fe(III)-enhanced anaerobic transformation of 2,4-dichlorophenoxyacetic acid by an iron-reducing bacterium Comamonas koreensis CY01," FEMS Microbiology Ecology, vol. 71, no. 1, pp. 106-113, 2010.

[74] S. Wang and W. A. Arnold, "Abiotic reduction of dinitroaniline herbicides," Water Research, vol. 37, no. 17, pp. 4191-4201, 2003.

[75] J. C. Xu, J. W. Stucki, J. Wu, J. E. Kostka, and G. K. Sims, "Fate of atrazine and alachlor in redox-treated ferruginous smectite," Environmental Toxicology and Chemistry, vol. 20, no. 12, pp. 2717-2724, 2001.

[76] M. Alexander and B. K. Lustigman, "Biodegradation: effect of chemical structure on microbial degradation of substituted benzenes," Journal of Agricultural and Food Chemistry, vol. 14, no. 4, pp. 410-413, 1966.

[77] G. K. Sims and L. E. Sommers, "Degradation of pyridine derivatives in soil," Journal of Environmental Quality, vol. 14, no. 4, pp. 580-584, 1985.

[78] D. M. Stamper and O. H. Tuovinen, "Biodegradation of the acetanilide herbicides alachlor, metolachlor, and propachlor," Critical Reviews in Microbiology, vol. 24, no. 1, pp. 1-22, 1998.

[79] A. M. Cupples, R. A. Sanford, and G. K. Sims, "Dehalogenation of the herbicides bromoxynil (3,5-dibromo-4-hydroxybenzonitrile) and ioxynil (3,5-diiodino-4-hydroxybenzonitrile) by Desulfitobacterium chlororespirans," Applied and Environmental Microbiology, vol. 71, no. 7, pp. 3741-3746, 2005.

[80] R. C. Doyle, D. D. Kaufman, and G. W. Burt, "Effect of dairy manure and sewage sludge on 14C-pesticide degradation in soil," Journal of Agricultural and Food Chemistry, vol. 26, no. 4, pp. 987-989, 1978.

[81] E. Barriuso, S. Houot, and C. Serra-Wittling, "Influence of compost addition to soil on the behaviour of herbicides," Pesticide Science, vol. 49, no. 1, pp. 65-75, 1997.

[82] S. Houot, E. Barriuso, and V. Bergheaud, "Modifications to atrazine degradation pathways in a loamy soil after addition of organic amendments," Soil Biology \& Biochemistry, vol. 30, no. 14, pp. 2147-2157, 1998.
[83] S. Alvey and D. E. Crowley, "Influence of organic amendments on biodegradation of atrazine as a nitrogen source," Journal of Environmental Quality, vol. 24, no. 6, pp. 1156-1162, 1995.

[84] J. A. Entry, K. G. Mattson, and W. H. Emmingham, "The influence of nitrogen on atrazine and 2,4-dichlorophenoxyacetic acid mineralization in grassland soils," Biology and Fertility of Soils, vol. 16, no. 3, pp. 179-182, 1993.

[85] F. M. Bento, F. A. O. Camargo, B. C. Okeke, and W. T. Frankenberger, "Comparative bioremediation of soils contaminated with diesel oil by natural attenuation, biostimulation and bioaugmentation," Bioresource Technology, vol. 96, no. 9, pp. 1049-1055, 2005.

[86] S. Liu and J. M. Suflita, "Ecology and evolution of microbial populations for bioremediation," Trends in Biotechnology, vol. 11, no. 8, pp. 344-352, 1993.

[87] P. J. Sturman, P. S. Stewart, A. B. Cunningham, E. J. Bouwer, and J. H. Wolfram, "Engineering scale-up of in situ bioremediation processes: a review," Journal of Contaminant Hydrology, vol. 19, no. 3, pp. 171-203, 1995.

[88] D. Lima, P. Viana, S. André et al., "Evaluating a bioremediation tool for atrazine contaminated soils in open soil microcosms: the effectiveness of bioaugmentation and biostimulation approaches," Chemosphere, vol. 74, no. 2, pp. 187-192, 2009.

[89] L. C. Strong, H. McTavish, M. J. Sadowsky, and L. P. Wackett, "Field-scale remediation of atrazine-contaminated soil using recombinant Escherichia coli expressing atrazine chlorohydrolase," Environmental Microbiology, vol. 2, no. 1, pp. 91-98, 2000.

[90] I. Robles-González, E. Ríos-Leal, R. Ferrera-Cerrato, F. Esparza-García, N. Rinderkenecht-Seijas, and H. M. PoggiVaraldo, "Bioremediation of a mineral soil with high contents of clay and organic matter contaminated with herbicide 2,4dichlorophenoxyacetic acid using slurry bioreactors: effect of electron acceptor and supplementation with an organic carbon source," Process Biochemistry, vol. 41, no. 9, pp. 19511960, 2006.

[91] G. R. Tortella, O. Rubilar, M. Cea, C. Wulff, O. Martinez, and M. C. Diez, "Biostimulation of agricultural biobeds with NPK fertilizer on chlorpyrifos degradation to avoid soil and water contamination," Journal of Soil Science and Plant Nutrition, vol. 10, no. 4, pp. 464-475, 2010.

[92] I. McGhee and R. G. Burns, "Biodegradation of 2,4dichlorophenoxyacetic acid (2,4-D) and 2-methyl-4chlorophenoxyacetic acid (MCPA) in contaminated soil," Applied Soil Ecology, vol. 2, no. 3, pp. 143-154, 1995.

[93] A. D. K. McBain, E. Senior, A. Paterson, C. A. du Plessis, and I. A. Watson-Craik, "Bioremediation of 4-chloro-2-methylphenoxyacetic acid (MCPA)-contaminated soil: microcosm and pilot field studies," South African Journal of Science, vol. 93, no. 5, pp. 226-230, 1997.

[94] A. Liaghat and S. O. Prasher, "A lysimeter study of grass cover and water table depth effects on pesticide residues in drainage water," Transactions of the American Society of Agricultural Engineers, vol. 39, no. 5, pp. 1731-1738, 1996.

[95] K. Isermann, "Share of agriculture in nitrogen and phosphorus emissions into the surface waters of Western Europe against the background of their eutrophication," Fertilizer Research, vol. 26, no. 1-3, pp. 253-269, 1990.

[96] M. Tyagi, M. M. R. da Fonseca, and C. C. C. R. de Carvalho, "Bioaugmentation and biostimulation strategies to improve the effectiveness of bioremediation processes," Biodegradation, vol. 22, no. 2, pp. 221-231, 2010. 

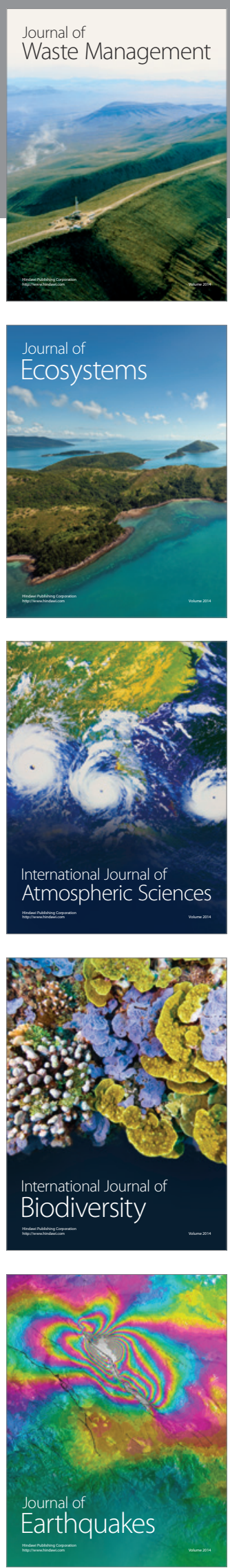
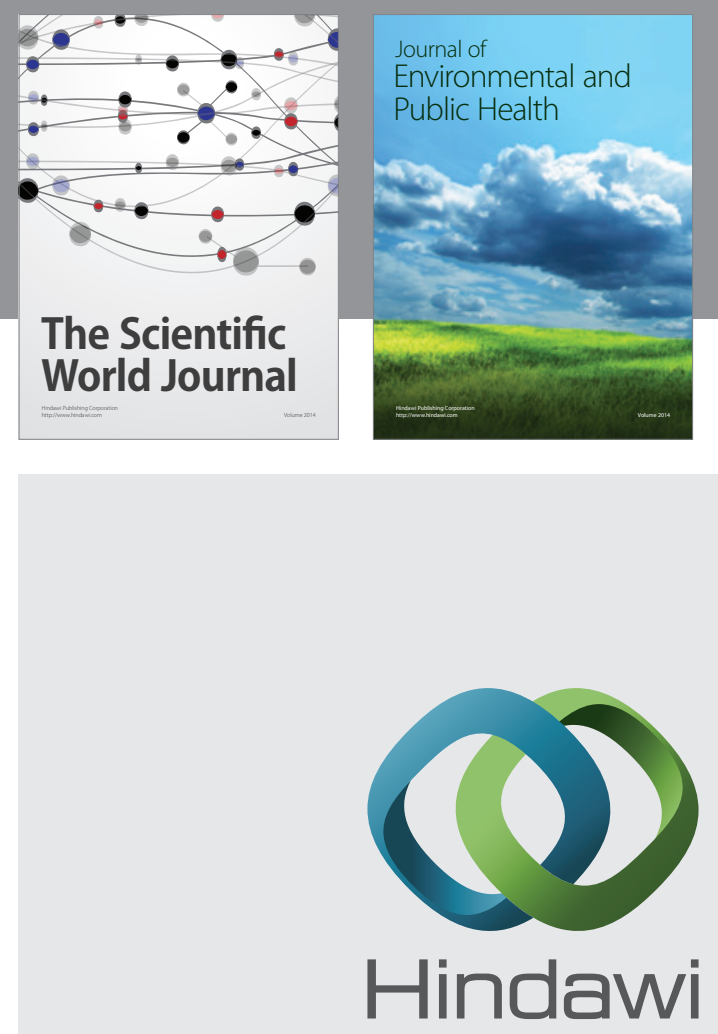

Submit your manuscripts at

http://www.hindawi.com
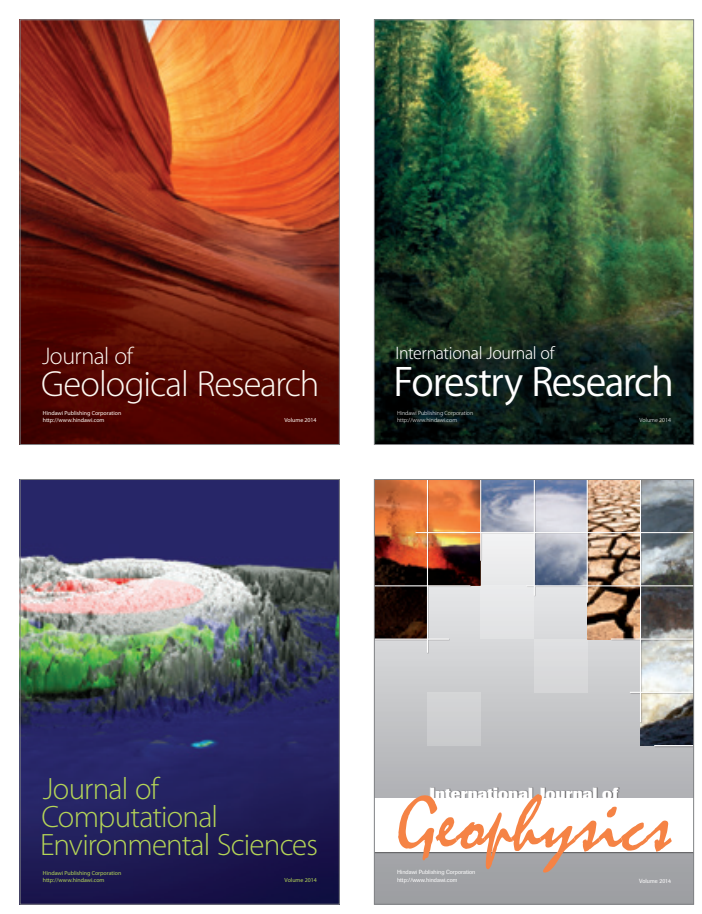
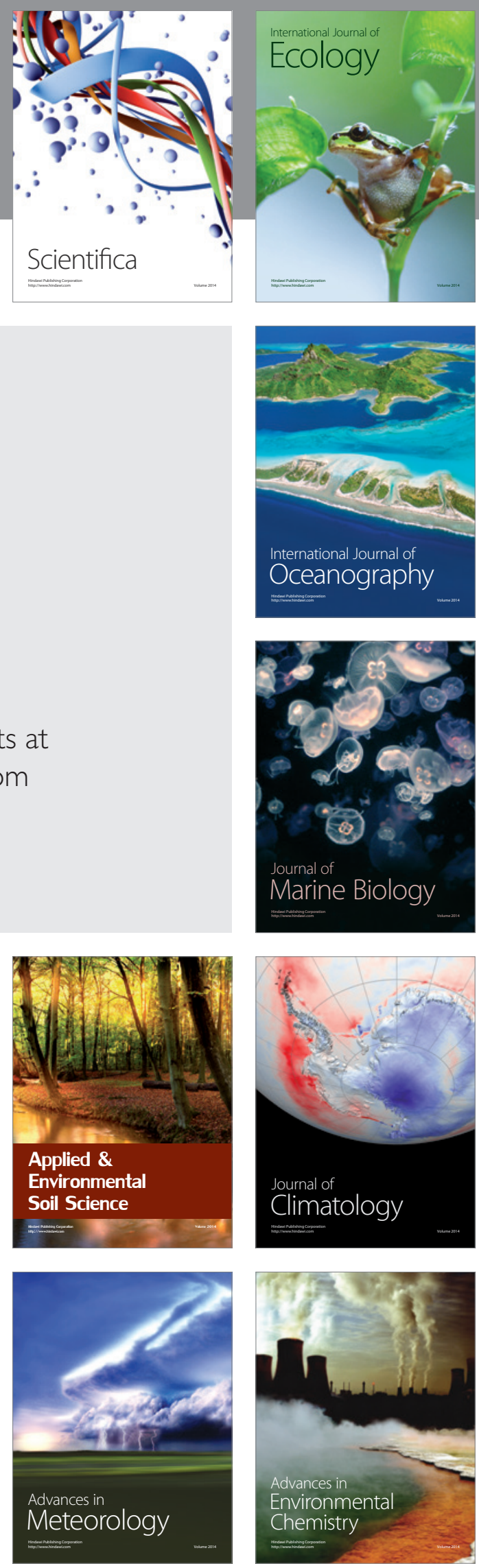